\title{
Characterisation of Saprolegnia sp. isolates from channel catfish
}

\author{
Eakaphun Bangyeekhun ${ }^{1}$, Sylvie M. A. Quiniou ${ }^{2}$, Jan E. Bly ${ }^{2}$, Lage Cerenius ${ }^{1, *}$ \\ ${ }^{1}$ Department of Comparative Physiology, Evolutionary Biology Centre, University of Uppsala, Norbyvägen 18A, \\ 75236 Uppsala, Sweden \\ ${ }^{2}$ Department of Microbiology, University of Mississippi Medical Center, Jackson, Mississippi 39216, USA
}

\begin{abstract}
Nineteen channel catfish isolates of Saprolegnia sp. obtained from 5 separate fish farms in Mississippi, which became affected by winter kill syndrome during 1991 and 1996, were investigated with respect to physiological characteristics and genetic variation. Isolates of $S$. parasitica from crayfish and $S$. diclina were included for comparison. Most strains of catfish isolates grew well at 20 and $30^{\circ} \mathrm{C}$. Repeated zoospore emergence was found in catfish isolates of Saprolegnia sp. and S. parasitica, but not in $S$. diclina. Random amplification of polymorphic DNA polymerase chain reaction (RAPD-PCR) was applied for a further characterisation of the isolates. The RAPD analysis among Saprolegnia spp. isolates was constructed from 686 amplified products in 67 separable positions and indicated that the catfish isolates of Saprolegnia sp. are composed of 3 genetically distinct groups.
\end{abstract}

KEY WORDS: Saprolegnia $\cdot$ Saprolegniosis $\cdot$ Fish disease $\cdot$ Random amplification of polymorphic DNA (RAPD)

\section{INTRODUCTION}

Infectious diseases caused by water molds cause losses of freshwater fish in both nature and commercial fish farms. Although several genera are parasitic on fish and their eggs (Scott \& O'Bier 1962, Noga 1993), the oomycete Saprolegnia spp. are known as one of the most important pathogens in freshwater fish, especially in salmonid species (Hatai \& Hoshiai 1992, Noga 1993, Diéguez-Uribeondo et al. 1996) and in channel catfish Ictalurus punctatus (Durborow et al. 1991, Bly et al. 1992).

Mass mortalities of farmed channel catfish are due to management factors and/or various pathogens (Durborow et al. 1991). During cold winters, mass mortalities, called the winter kill syndrome, occur with fungal skin lesions, dry skin and endophthalmia (Durborow \& Crosby 1988). One pathogen, Saprolegnia sp., plays an important role in causing winter kill syndrome in channel catfish, and therefore the disease was named winter saprolegniosis (Bly et al. 1992).

${ }^{*}$ Corresponding author. E-mail: lage.cerenius@ebc.uu.se
Characterisation of subgroups within species of Saprolegnia spp. are necessary to understand its ecology and epidemiology. Genetic characterisation by random amplified polymorphic DNA (RAPD) of Aphanomyces astaci, the crayfish plague fungus, made it possible to trace the origin of infections and to establish that introduced foreign host crayfish have given rise to the spread of new genotypes of the parasite (Huang et al. 1994, Lilley et al. 1997, Vennerström et al. 1998). In the present study, random amplification of polymorphic DNA polymeras chain reaction (RAPDPCR) analysis is applied and some ecophysiological parameters such as repeated zoospore emergence and mycelial growth are used to characterise genetic and physiological variations within Saprolegnia sp. isolated from channel catfish during different outbreaks of winter saprolegniosis.

\section{MATERIALS AND METHODS}

Saprolegnia strains. Saprolegnia isolates were obtained from skin lesions on moribund catfish exhibiting 
signs of winter saprolegniosis (formerly termed winter kill syndrome). In the case of one fish, isolates were obtained from the eye and fin. All catfish were obtained from catfish farms, at least 50 miles $(\sim 80 \mathrm{~km})$ apart, but located within the Mississippi Delta, USA. Isolates obtained in 1991 are designated CF91 and comprise CF91-1 (now deposited in the American Type Culture Collection; ATCC \# 200048), CF91-2, CF91-4, CF91-5, CF91-6 and CF91-9. All 1991 isolates were collected from different fish in one pond at Dyche Plantation catfish farm (designated Farm 1, Table 1; Bly et al. 1992, wherein these isolates are referred to as CF1 through CF9). All other isolates collected from catfish were obtained in 1996 and are designated as CF96. CF96-1 through CF96-13 were obtained from different places of origin (see Table 1) in order to determine if geography had an effect on Saprolegnia spp. genetic variation. Four farms were sampled in 1996, TAM-AN (Farm 2), Holly Ridge (Farm 3), Topcat (Farm 4) and Higg (Farm 5). Other strains, i.e. S. parasitica (Spt) isolated from freshwater crayfish Astacus leptodactylus (Söderhäll et al. 1991) and S. diclina (Sdi; ATCC \# 42062), were included for comparison. All isolates were maintained on PG-1 agar medium (Unestam 1965).

Hyphal radial growth rate. The inoculum was prepared by cutting at the advancing edges of a young colony grown on PG-1 agar with a $6 \mathrm{~mm}$ diameter

Table 1. Isolates of Saprolegnia spp. used for RAPD analysis. Superscripts 1, 2, 3,4 and 5 denote clusters with $100 \%$ identity

\begin{tabular}{|c|c|c|c|c|c|}
\hline $\begin{array}{l}\text { Saprolegnia } \\
\text { isolate }\end{array}$ & $\begin{array}{r}\text { Pl } \\
\text { Farm no. }\end{array}$ & $\begin{array}{l}\text { ace of orig } \\
\text { Pond no. }\end{array}$ & $\begin{array}{l}\text { in } \\
\text { Fish no. }\end{array}$ & $\begin{array}{l}\text { Repeated zoospore } \\
\text { emergence }(\%)\end{array}$ & $\begin{array}{l}\text { RAPD } \\
\text { group }\end{array}$ \\
\hline CF91-1 & 1 & 1 & 1 & 98 & $1^{1}$ \\
\hline CF91-2 & 1 & 1 & 2 & 97 & $1^{1}$ \\
\hline CF91-4 & 1 & 1 & 3 & $55^{\mathrm{a}}$ & 1 \\
\hline CF91-5 & 1 & 1 & 4 & $55^{\mathrm{a}}$ & 1 \\
\hline CF91-6 & 1 & 1 & 5 & $50^{\mathrm{a}}$ & 1 \\
\hline CF91-9 & 1 & 1 & 6 & 97 & 1 \\
\hline CF96-1 & 2 & 1 & 1 & 97 & $1^{2}$ \\
\hline CF96-2 & 2 & 1 & 2 & 98 & $3^{3}$ \\
\hline CF96-3 & 2 & 1 & 3 (eye) & 98 & 1 \\
\hline CF96-4 & 2 & 1 & 3 (fin) & 98 & $3^{3}$ \\
\hline CF96-5 & 2 & 2 & 1 & 95 & $1^{2}$ \\
\hline CF96-6 & 2 & 2 & 2 & 95 & $1^{2}$ \\
\hline CF96-7 & 2 & 2 & 3 & 95 & $1^{2}$ \\
\hline CF96-8 & 3 & 1 & 1 & 98 & $2^{4}$ \\
\hline CF96-9 & 3 & 1 & 2 & 98 & $2^{4}$ \\
\hline CF96-10 & 4 & 1 & 1 & 95 & $3^{5}$ \\
\hline CF96-11 & 4 & 1 & 2 & 98 & $3^{5}$ \\
\hline CF96-12 & 5 & 1 & 1 & 99 & $3^{5}$ \\
\hline CF96-13 & 5 & 1 & 2 & 95 & 1 \\
\hline Spt (S. parasitica) & - & - & - & 98 & \\
\hline Sdi (S. diclina) & - & - & - & $<2$ & \\
\hline
\end{tabular}

borer. The different Saprolegnia isolates were inoculated on a fresh PG-1 agar dish. The colony hyphal radial growth rates were determined as described by Trinci (1969) at 20 and $30^{\circ} \mathrm{C}$. Comparisons of hyphal growth rate between isolates were made using a Student's $t$-test. Differences were considered significant at $\mathrm{p} \leq 0.05$.

Repeated zoospore emergence. Repeated zoospore emergence was performed according to the method described by Diéguez-Uribeondo et al. (1994). Briefly, mycelia were grown in PG-1 drop cultures for $3 \mathrm{~d}$ at $20^{\circ} \mathrm{C}$. To trigger sporulation, the mycelia were washed 3 times with sterile lake water and then incubated in Petri dishes containing lake water for $14 \mathrm{~h}$ at $20^{\circ} \mathrm{C}$ to allow the release of zoospores. The swimming zoospores were transferred to the test tubes, which were then agitated in a vortex mixer for $45 \mathrm{~s}$ to obtain synchronous encystment. The release of secondary zoospores was observed under the microscope after incubating the cyst suspension at $20^{\circ} \mathrm{C}$ for $150 \mathrm{~min}$.

DNA isolation. A small piece of mycelium (approximately 1.5 mg dry weight) grown in PG-1 drop culture was inoculated in a $100 \mathrm{ml}$ flask containing $25 \mathrm{ml}$ PG-1 medium and cultured by shaking at $20^{\circ} \mathrm{C}$. After $3 \mathrm{~d}$, the mycelia were harvested, washed with sterile water and ground in liquid nitrogen with a mortar. The total genomic DNA was extracted using Nucleon II Kit, following the supplied procedure for filamentous fungi (Nucleon Biosciences, UK). The DNA extracts were stored at $-20^{\circ} \mathrm{C}$ until required.

RAPD-PCR. The PCR reactions were carried out in $50 \mu \mathrm{l}$ volumes containing 100 ng mycelial DNA, 10 mM Tris$\mathrm{HCl}(\mathrm{pH} 8.6), 50 \mathrm{mM} \mathrm{KCl}, 1.5 \mathrm{mM}$ $\mathrm{MgCl}_{2}, 0.1 \%$ Triton X-100, $0.2 \mathrm{mM}$ of each dNTP (Amersham Pharmacia Biotech), $0.4 \mu \mathrm{M}$ primer (Operon; described below) and either (1) 2.5 units of Taq DNA polymerase (Amersham) and $0.55 \mu \mathrm{g}$ of Taqstart Antibody (Clontech) were added to the PCR mixture, or (2) 2.5 units of Taq DNA polymerase were added after heating the reaction mixture to $80^{\circ} \mathrm{C}$. Amplifications were performed in a Perkin Elmer GeneAmp PCR system 2400 programmed for 1 cycle of initial denaturation at $94^{\circ} \mathrm{C}$ for $5 \mathrm{~min}$ and $80^{\circ} \mathrm{C}$ for $2 \mathrm{~min}, 45$ cycles of denaturation at $94^{\circ} \mathrm{C}$ for $1 \mathrm{~min}$, annealing at $36^{\circ} \mathrm{C}$ for $1 \mathrm{~min}$ and extension at $72^{\circ} \mathrm{C}$ for $2 \mathrm{~min}$, and a final extension at $72^{\circ} \mathrm{C}$ for $7 \mathrm{~min}$. The PCR products were then stored at $4^{\circ} \mathrm{C}$. Ten $\mu$ of PCR products were 
separated on $1.5 \%$ agarose gel and 100 bp Ladder DNA (Amersham Pharmacia Biotech) was used as a molecular weight marker. Gels were stained with ethidium bromide, visualized by UV illumination and photographed with a Polaroid camera. The following primers were used: A04 (5'-AATCGGGCTG-3'), A05 (5'-AGGGGTCTTG-3'), A06 (5'-GGTCCCTGAC-3'), A07 (5'-GAAACGGGTG-3'), A10 (5'-GTGATCGCAG3'), A12 (5'-TCGGCGATAG-3'), A20 (5'-GTTGCGATCC-3'), and B01 (5'-GTTTCGCTCC-3').

Data analysis. The RAPD-PCR was performed at least twice, and only reproducibly amplified markers were scored as present (1) or absent (0). Similarity coefficients $(F)$ between 2 isolates were calculated according to the formula of Nei \& $\mathrm{Li}(1979) ; F=2 N_{x y} / N_{x}+$ $N_{y}$, where $N_{x y}$ is the number of common fragments between 2 isolates, and $N_{X}$ and $N_{Y}$ are the number of fragments in isolates $X$ and $Y$, respectively. Pooled data from 8 primers were used for this calculation.

\section{RESULTS}

\section{Hyphal radial growth rates}

The hyphal radial growth rates of all Saprolegnia isolates were investigated at different temperatures. At $20^{\circ} \mathrm{C}$, one catfish isolate (CF91-1) grew slower than all other Saprolegnia isolates $(\mathrm{p} \leq 0.0001$; Fig $1 \mathrm{~A})$. At $30^{\circ} \mathrm{C}$, isolate CF96-8 grew significantly more slowly than all other isolates ( $\mathrm{p} \leq 0.0001$; Fig 1B).

\section{Repeated zoospore emergence}

Repeated zoospore emergence is the capacity of an encysted spore to release a new zoospore generation instead of germinating. The Saprolegnia parasitica strain and most isolates of $\mathrm{Sa}$ prolegnia sp. from catfish could produce secondary zoospores after encystment, while the $S$. diclina cysts instead underwent germination. However, in isolates CF91-4, CF91-5 and CF916 , we found a combination of germinated cysts and second generation zoospores together in about equal proportions after they were encysted mechanically (Table 1).

\section{Amplification of Saprolegnia isolates genomic DNA}

In preliminary experiments, 15 arbitrary 10-mer primers were tested for their ability to consistently produce amplification products from the different test strains of Saprolegnia spp. isolates. The 8 primers listed in 'Materials and methods' gave consistent results and produced a reasonable number of identifiable and polymorphic bands. They produced in total 686 clearly amplified PCR bands in 67 different positions, and the average number of bands per isolate was 32.7. The number of amplified DNA fragments generated by each RAPD primer ranged from 4 (primer A06) to 10 (primers A10 and A12). The size of the fragments produced ranged from 400 to $1800 \mathrm{bp}$ and there were 27 positions, i.e. $40.3 \%$ of total, with a product size larger than $1 \mathrm{~kb}$. An example of an RAPD pattern generated by primer A07 is shown in Fig. 2A.

The RAPD profiles obtained by using the A06 primer on 21 Saprolegnia spp. isolates gave 4 distinguishable PCR markers (Fig. 2B). Of these, 2 fragments, i.e. 380 and $1700 \mathrm{bp}$, were consistently present in all isolates whereas a $420 \mathrm{bp}$ product was present in all isolates except the $S$. diclina isolate, and a $600 \mathrm{bp}$ fragment was present in CF96-10, CF96-11 and CF96-12. It is possible that the $420 \mathrm{bp}$ product could be useful for the development of diagnostic tools within the $S$. parasitica-diclina complex.
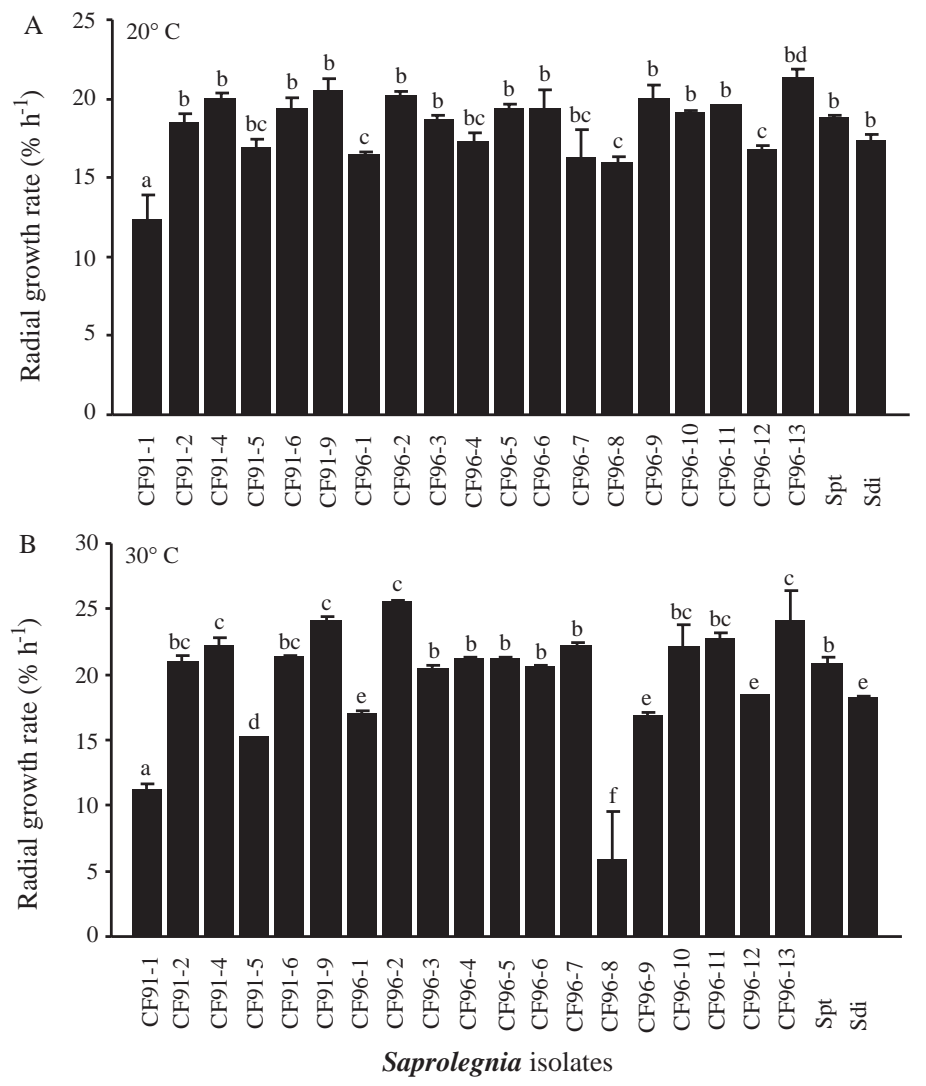

Fig. 1. Radial growth rate of Saprolegnia spp. isolates on PG-1 agar at (A) $20^{\circ} \mathrm{C}$ and (B) $30^{\circ} \mathrm{C}$. Growth rates were calculated from colonies growing at a constant rate. Values are means of 3 independent experiments. Vertical bars indicate standard deviation of the means 

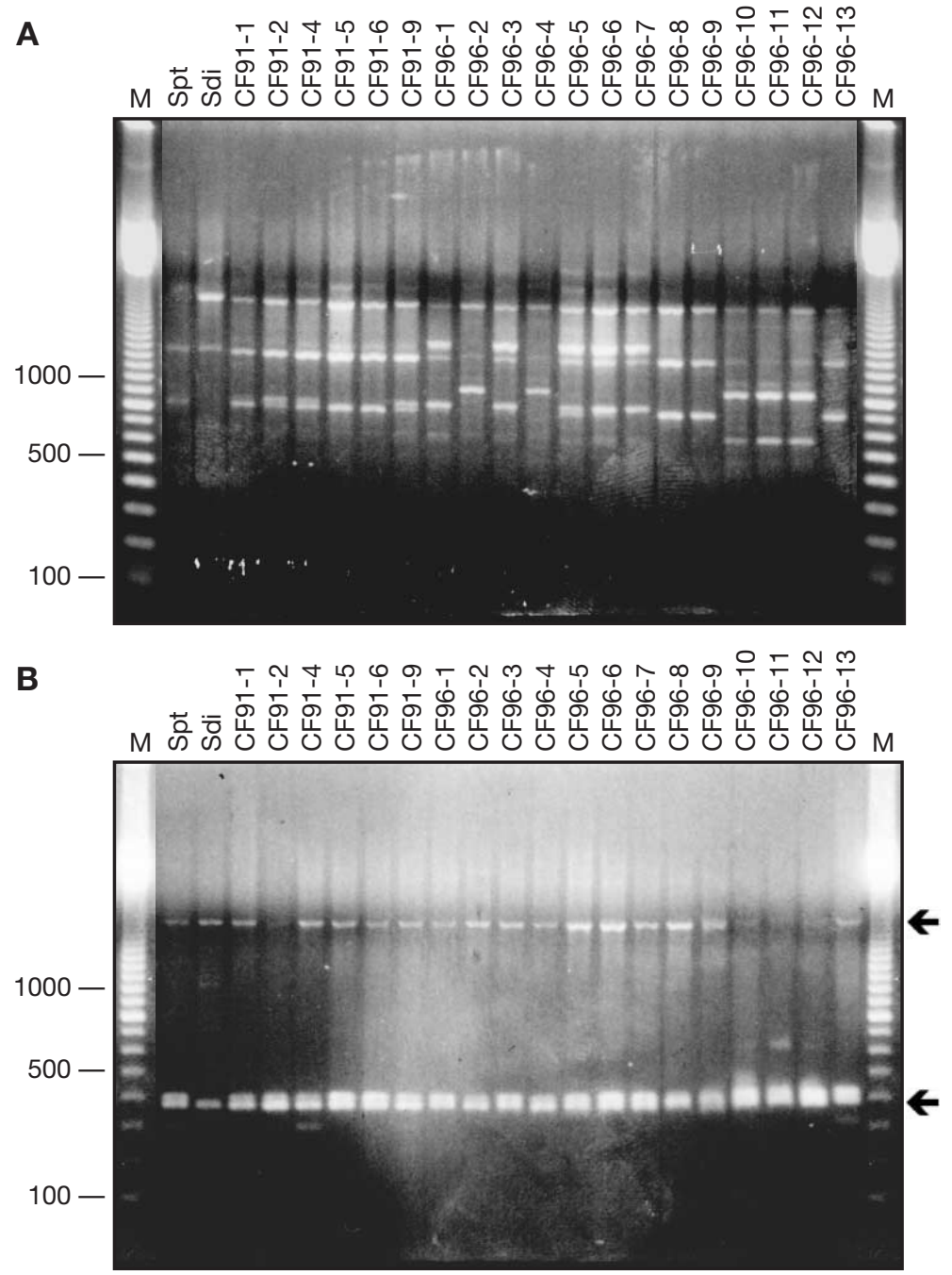

Fig. 2. Amplification of genomic DNA from different Saprolegnia spp. isolates using primers (A) A07 and (B) A06. From the left in both (A) and (B), 100 bp ladder size marker (M), Spt, Sdi, CF91-1, CF91-2, CF91-4, CF91-5, CF91-6, CF91-9, CF96-1, CF96-2, CF96-3，CF96-4，CF96-5, CF96-6, CF96-7, CF96-8, CF96-9, CF96-10, CF96-11, CF96-12, CF96-13 and 100 bp ladder size marker (M). (B) To the right, the upper arrow indicates the position of the band which appears to be specific for Saprolegnia isolates, and the lower arrow indicates the position of the band which appears to be specific for isolates of Saprolegnia sp. from catfish and $S$. parasitica (Spt)

\section{Genetic variation among isolates based on analysis of RAPD pattern}

All PCR fragments obtained were utilised for genetic distance analysis. A similarity matrix indicated that the 19 American catfish isolates can be grouped into 3 distinct groups (Table 1). The first group (Group 1, Table 1) is composed of CF91-1 through CF91-9, CF96-1, CF96-3, CF96-5, CF96-6, CF96-7 and CF96-13. The second group (Group 2, Table 1) is formed by 2 isolates of
CF96-8 and CF96-9. The final group (Group 3, Table 1) consists of CF96-2, CF96-4 and CF96-10 through CF96-12. Within each group, members share at least $80 \%$ of the PCR products except for CF96-13, which showed 70 to $80 \%$ similarity to members in Group 1 (Table 2). Furthermore, within the groups, clusters of $100 \%$ identity were found (Table 1, Cluster 1 to 5 and Table 2), i.e. Cluster 1, CF91-1 and CF91-2; Cluster 2, CF96-1, and CF96-5 through CF96-7; Cluster 3, CF96-2 and CF96-4; Cluster 4, CF96-8 and CF96-9; and Cluster 5, CF96-10 through CF96-12. With the exception of Cluster 5, isolate clusters with $100 \%$ identity came from the same pond. While all Saprolegnia sp. isolates obtained in 1991 fell into Group 1, only 2 isolates were $100 \%$ identical (CF91-1 and CF91-2); furthermore 6 isolates obtained in 1996 also fell into Group 1. While Group 2 is unique to Farm 3, Group 3 contained isolates from 3 farms. Only 1 fish (Farm 2, Pond 1, Fish 3; Table 1) was sampled for Saprolegnia sp. from the eye as well as a fin skin lesion. The isolates from the eye (CF96-3) fell into Group 1 while the isolate from the fin (CF964) fell into Group 3, demonstrating that at least 2 strains of Saprolegnia co-existed in the same pond and were able to infect different organs in 1 fish. Isolate CF96-4, from the fin, exhibited $100 \%$ identity with isolate CF96-2, which was sampled from Fish 2 in Pond 1 (both were designated Group 3, Cluster 3). This indicates that similar strains of pathogenic Saprolegnia sp. do not exhibit organ specificity.

Saprolegnia sp. isolates in Group 1 are distantly related to Group 2 and Group 3, with average similarity coefficients of 0.730 and 0.539 , respectively. The average similarity coefficient for Group 2 and Group 3 was 0.525 . The corresponding value of $S$. parasitica isolated from freshwater crayfish (Spt) and $S$. diclina (Sdi), which were included for comparison, was 0.522 and they showed a low level of similarity $(<70 \%)$ to all catfish isolates (Table 2).

\section{DISCUSSION}

The RAPD profiles obtained in this study revealed a genetic variation among catfish isolates and separated the isolates into 3 different groups. Group 1 contained isolates obtained from 1991 and 1996, indicating that 


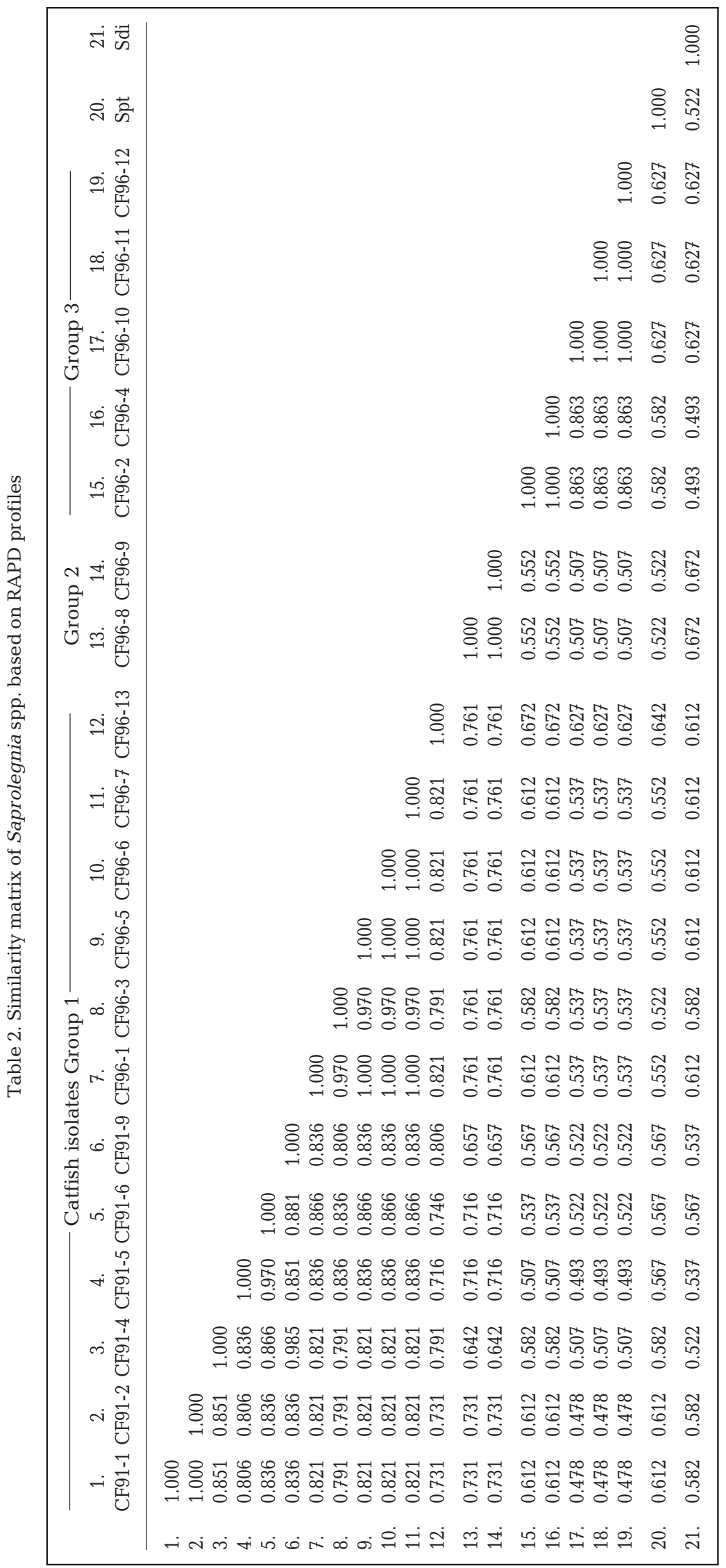

the group of closely related strains has persisted for over $5 \mathrm{yr}$ in this area. The remaining catfish isolates from 1996 could be divided into Group 2 and Group 3. It is of interest to note that these groups were not farm specific. Saprolegnia sp. isolates of Group 1 were found in Farms 1, 2 and 5 and isolates of Group 3 are shown in Farms 2, 4 and 5. This spread of a group of closely related strains in Mississippi is in agreement with Diéguez-Uribeondo et al. (1996), who compared different isolates of Saprolegnia parasitica from trout by the RAPD-PCR technique and demonstrated that a group of closely related strains was spread over a large area and isolated from each other in well separated water systems. The Delta region of Mississippi is a vast area and has over 150000 acres of catfish ponds. It is likely that the spread of Saprolegnia sp. from pond to pond on one farm may be caused by farming management, and the spread from farm to farm may be due to birds, which feed on the catfish.

Many pathogenic strains of Saprolegnia spp. isolated from fish lesions apparently lack a sexual stage (Beakes \& Ford 1983) including these catfish isolates. One would assume that asexual reproduction or sexual propagation in homothallic strains may lead to clonal propagation, i.e. a single genotype becomes widely spread. This may explain the high degree of homology within Saprolegnia sp. strains on a farm. Malvick \& Percich (1998) assessed pathogenic and genotypic variation in Aphanomyces euteiches expressed through asexually reproduced zoospores. The small RAPD pattern variations within single-zoospore progenies suggest that some genetic changes might occur in $A$. euteiches during asexual reproduction. Therefore, it is possible that the genetic diversity observed between catfish Saprolegnia sp. isolates within each group, from a single pond, may be caused by events during the asexual phase of reproduction (such as mitotic cross-overs, mutations or somatic recombination). Highly variable parasite populations, in general, are better adapted to changes in environmental conditions 
than those with little variation. The presence of at least 3 very distinct groups or strains of Saprolegnia sp. in the Mississippi Delta indicates that there are mechanisms to ensure that variable genotypes are spread in asexual Saprolegnia.

Physiological properties of Saprolegnia have been used for the classification of different subgroups within a species. Studies with esterase isoenzyme patterns (Beakes \& Ford 1983) and the relationships between growth rate and temperature (Willoughby \& Copland 1984, Hatai et al. 1990) identified different groups of fish lesion isolates. In this study, there were differences between the hyphal radial growth rate of Saprolegnia sp. isolates at both 20 and $30^{\circ} \mathrm{C}$ (Fig. 1). It is of interest that $100 \%$ genetically similar isolates (as determined by RAPD), i.e. (1) CF91-1 to CF91-2, and (2) CF96-8 to CF96-9, exhibited significant differences in hyphal radial growth rate at 20 and $30^{\circ} \mathrm{C}$. This result indicates that the variability in growth characteristics in the present study cannot be detected by RAPD-PCR. This is perhaps not too surprising considering that an altered growth rate may be caused by a mutation affecting a single or a few genes and thus not likely to be detected by the RAPD-PCR analysis. Willoughby \& Copland (1984) studied temperaturegrowth relationships of Saprolegnia isolated from different fish and reported the presence of mutant daughter isolates obtained from the periphery of the dying, original colony when grown at high temperature. These daughter colonies not only showed similar growth rate at original temperature as the parent strains, but they also exhibited an adaptation to high temperature. This event was suggestive of induction of cytoplasmic rather than a genetic change. In contrast, Hatai et al. (1990) studied daughter colonies of Saprolegnia isolates that stably expressed a slowgrowing phenotype and were suggested to be true genetic mutants. Possibly, our slowest growing isolates, i.e. CF91-1 and CF96-8, are stable mutants since repeated subculturing did not affect their growth rates.

Saprolegnia parasitica isolated from crayfish and the catfish isolates exhibited repeated zoospore emergence, whereas the $S$. diclina isolate did not. Repeated zoospore emergence has been reported in Aphanomyces spp. and was proposed to be an adaptation to a parasitic mode of life (Cerenius \& Söderhäll 1985). The presence of repeated zoospore emergence in Saprolegnia isolates may be useful for colonizing fish skin. However, Diéguez-Uribeondo et al. (1996) reported that the trout isolates of $S$. parasitica did not exhibit this phenomenon. Thus, repeated zoospore emergence is not a specific mechanism for pathogenic Saprolegnia isolates since some fish-pathogenic isolates exhibit germination after encystment.
In summary, the application of the RAPD technique to characterise genetic variation of Saprolegnia spp. reveals the presence of several strains within a wide area during outbreaks of winter kill syndrome and that at least 1 group of closely related strains (Group 1) has persisted for $5 \mathrm{yr}$ in this area. These results indicate that, in the future, genetics may be used to monitor the persistence and spread of the pathogen. Comparing genetics with physiological adaptations such as temperature tolerance, pathogenicity and zoospore behavior may reveal genetic markers, which can identify and monitor strains of Saprolegnia particularly harmful to the fish farming industry.

Acknowledgements. Grateful thanks to Ragnar Ajaxon for technical assistance. E.B. was funded by a scholarship from the Royal Thai Government. This work was financed by grants from the Swedish Council for Forestry and Agricultural Research to Kenneth Söderhäll and from Carl Tryggers Stiftelse to Lage Cerenius.

\section{LITERATURE CITED}

Beakes GW, Ford H (1983) Esterase isozyme variation in genus Saprolegnia, with particular reference to the fishpathogenic Saprolegnia diclina-parasitica complex. J Gen Microbiol 129:2605-2619

Bly JE, Lawson LA, Dale DJ, Szali AJ, Durborow RM, Clem LW (1992) Winter saprolegniosis in channel catfish. Dis Aquat Org 13:155-164

Cerenius L, Söderhäll K (1985) Repeated zoospore emergence as a possible adaptation to parasitism in Aphanomyces. Exp Mycol 8:370-377

Diéguez-Uribeondo J, Cerenius L, Söderhäll K (1994) Repeated zoospore emergence in Saprolegnia parasitica. Mycol Res 98:810-815

Diéguez-Uribeondo J, Cerenius L, Söderhäll K (1996) Physiological characterisation of Saprolegnia parasitica isolates from brown trout. Aquaculture 140:247-257

Durborow RM, Crosby MD (1988) Monitoring winter kill conditions can cut losses. Catfish J 3:9

Durborow RM, Taylor PW, Crosby MD, Santucci TD (1991) Fish mortality in Mississippi catfish farming industry in 1988: causes and treatments. J Wildl Dis 27:144-147

Hatai K, Hoshiai G (1992) Mass mortality in cultured coho salmon (Oncorhynchus kisutch) due to Saprolegnia parasitica Coker. J Wildl Dis 28:532-536

Hatai K, Willoughby LG, Beakes GW (1990) Some characteristics of Saprolegnia obtained from fish hatcheries in Japan. Mycol Res 94:182-190

Huang T, Cerenius L, Söderhäll K (1994) Analysis of genetic diversity in crayfish plague fungus, Aphanomyces astaci, by random amplification of polymorphic DNA. Aquaculture 126:1-10

Lilley JH, Cerenius L, Söderhäll K (1997) RAPD evidence for the origin of crayfish plague outbreaks in Britain. Aquaculture 157:181-185

Malvick DK, Percich JA (1998) Variation in pathogenicity and genotype among single-zoospore strains of Aphanomyces euteiches. Phytopathology 88:52-57

Nei M, Li WH (1979) Mathematical model for studying genetic variation in terms of restriction endonuclease. Proc Natl Acad Sci USA 76:5269-5273 
Noga EJ (1993) Water mold infection of fresh water fish: recent advances. Annu Rev Fish Dis 3:291-304

Scott WW, O'Bier AH (1962) Aquatic fungi associated with diseased fish and fish eggs. Progressive Fish-Culturist $24: 3-15$

Söderhäll K, Dick MW, Clark G, Fürst M, Constantinescu O (1991) Isolation of Saprolegnia parasitica from the crayfish Astacus leptodactylus. Aquaculture 92:121-125

Trinci APJ (1969) A kinetic study of the growth of Aspergillus nidulans and other fungi. J Gen Microbiol 57:11-24

Editorial responsibility: David Bruno,

Aberdeen, Scotland, UK
Unestam T (1965) Studies on the crayfish plague fungus Aphanomyces astaci. I. Some factors affecting growth in vitro. Physiol Plant 18:483-505

Vennerström P, Söderhäll K, Cerenius L (1998) The origin of two crayfish plague (Aphanomyces astaci) epizootics in Finland on noble crayfish Astacus astacus. Ann Zool Fenn 35:43-46

Willoughby LG, Copland JW (1984) The temperature-growth relationships of Saprolegnia pathogenic to fish, especially eels cultivated in warm water. Nova Hedwigia 39:35-55

Submitted: October 26, 2000; Accepted: January 29, 2001 Proofs received from author(s): April 23, 2001 